\title{
Prevalence of Anxiety and Depression Among Cancer Patients During the COVID-19 Pandemic: a Systematic Review and Meta-analysis
}

Hongping Yu ( $\nabla$ yuhongping@stu.gxmu.edu.cn )

guangxi medical university cancer hospital

\section{Zewen Zhou}

Guangxi Medical University

Qiuyan Mo

Guangxi Medical University

Xianguo Zhou

Guangxi Cancer Hospital and Guangxi Medical University Affiliated Cancer Hospital

Yingchun Liu

Guangxi Cancer Hospital and Guangxi Medical University Affiliated Cancer Hospital

Shixiong Feng

Guangxi Medical University

\section{Research}

Keywords: anxiety, cancer patients, COVID-19, depression, mental health

Posted Date: December 28th, 2020

DOI: https://doi.org/10.21203/rs.3.rs-133466/v1

License: (a) (i) This work is licensed under a Creative Commons Attribution 4.0 International License.

Read Full License 


\section{Abstract}

Background: The COVID-19 pandemic has significantly affected patients' access to healthcare. Patients with malignant tumors have experienced treatment interruptions and difficulties in seeking medical attention, and these have affected their mental health. The objective of this review is to evaluate the current evidence on the prevalence of depression and anxiety in cancer patients during the COVID-19 pandemic.

Methods: We searched the EMBASE, PubMed, WHO COVID-19 database, Cochrane Library, Web of Science, CBM, CNKI, Wanfangdata, CQVIP, and CBM electronic databases for relevant studies published from the first available day to June 30,2020. Two researchers independently screened the literature based on predetermined criteria and assessed the risk of bias in each study. Random-effects meta-analyses was used to estimate the pooled prevalence of anxiety and depression among patients with malignant tumors. The review protocol has been registered in PROSPERO (CRD42020196421).

Results: Nine eligible studies on 2,335 patients with malignant tumors were included, all of which were cross-sectional studies. The pooled prevalence of anxiety was $52.94 \%\left(95 \% \mathrm{Cl}: 36.98 \%-68.91 \%, l^{2}=98.6 \%\right)$ in 9 studies, and the pooled prevalence of depression was $43.25 \%\left(95 \% \mathrm{Cl}: 25.85 \%-60.85 \%, P^{2}=98.8 \%\right.$ ) in 6 studies.

Conclusions: Evidence shows that a considerable proportion of patients with malignant tumors suffered from emotional distress during the COVID-19 pandemic. It is important to solve the problem of interruption or delay of treatment and strengthen psychological interventions for patients with malignant tumors during the pandemic.

\section{Introduction}

In December 2019, cases of pneumonia of unknown etiology were detected in Wuhan City, Hubei Province of China and attracted intense worldwide attention ${ }^{1}$. On March 11 2020, the World Health Organization (WHO) declared the COVID-19 a global pandemic ${ }^{2}$. During the COVID-19 pandemic, delivery of cancer treatment ${ }^{3,4}$, cancer care ${ }^{5,6}$, and cancer screening ${ }^{7,8}$ has become challenging. Many cancer patients suffer from interruption or delay of cancer treatment due to the pandemic crisis, and while this may reduce the risk of COVID-19 infection and death, it may also increase cancer-specific mortality ${ }^{9}$.

Anxiety and depression are the common types of emotional distress in cancer patients. Among cancer survivors, the prevalence of anxiety and depression is higher than that in the general population ${ }^{10-12}$. In two major provincial cancer centers of Canada, $19.0 \%$ of cancer patients showed clinical anxiety and another $22.6 \%$ showed subclinical symptoms, $12.9 \%$ of cancer patients reported clinical depression symptoms and an additional $16.5 \%$ displayed subclinical symptoms ${ }^{10}$. Negative emotions such as anxiety and depression can bring negative effects to cancer patients, such as increased side effects of treatment, slow physical recovery, reduced quality of life and survival rates ${ }^{13-15}$. 
The risk of COVID-19 infection and the interruption of cancer treatment are likely to aggravate the anxiety and depression symptoms of cancer patients and further affect their clinical cancer prognosis. To our knowledge, there has not been a systematic review done on the prevalence of anxiety and depression in cancer patients during the COVID-19 epidemic. The prevalence figures reported thus far also varied widely. Therefore, the purpose of this systematic review and meta-analysis is to understand the impact of the COVID-19 outbreak on the prevalence of anxiety and depression in patients with malignant tumors, and to provide a basis for the need for psychological intervention for this group.

\section{Methods}

\section{Protocol and guidance}

This systematic review was based on the PRISMA statement ${ }^{16}$ following the recommendations of the Meta-analysis Of Observational Studies in Epidemiology (MOOSE) group ${ }^{17}$. The review protocol has been registered at PROSPERO (CRD42020196421) and can be obtained online (https://www.crd.york.ac.uk/prospero/).

\section{Research strategy and selection criteria}

Two researchers (Zewen Zhou, Qiuyan Mo) independently searched electronic databases such as the EMBASE, PubMed, WHO COVID-19 database, Cochrane Library, Web of Science, CBM, CNKI, Wanfangdata and CQVIP for relevant studies from the first available day to June 30, 2020. These studies have reported the prevalence of depression and anxiety during the COVID-19 pandemic. The following search terms were used: ("cancer" OR "neoplasms" OR "malignancy" OR "tumor" OR "carcinoma") and ("2019 novel coronavirus" OR "COVID-19" OR "SARS-CoV-2" OR "2019-nCov" OR "novel coronavirus pneumonia") and ("depression" OR "anxiety" OR "mental health" OR "psychological”). "Snowball sampling" was performed on each retrieved article by searching reference lists and citation tracking. The research language of the search was limited to English and Chinese. The two researchers independently evaluated the full text according to predetermined criteria.

The subjects were set as those aged 18 years and above, currently or previously diagnosed with malignant tumors, and are living in countries or regions affected by COVID-19. Only studies that used validated assessment methods to assess the prevalence of anxiety and depression were eligible for inclusion. Studies that use broad terms such as "psychological distress" or "emotional distress" were excluded.

\section{Data extraction and quality assessment}

The following data were independently extracted from each article using a standardized format: author's name, country or region, sample size, number of males or females, disease characteristics, percentage of anxiety or depression, assessment methods used and their cut-offs. If such information were not reported, the necessary calculations were made where possible (for example, the number and percentage of patients with malignant tumors). When encountered with inconsistent data, we checked the accuracy of 
the data against the original literature. Disagreement was resolved through discussion. Uncertainties or missing data in the literature were verified or supplemented by contacting the author.

According to the Agency for Healthcare Research and Quality (AHRQ) recommendations, an 11-item checklist for cross-sectional studies were used to assess the methodological quality of studies by two authors independently ${ }^{18}$. If it was answered 'YES', the item was scored ' 1 '; if it was answered 'UNCLEAR' or 'NO', the item was scored ' $O$ '. The third author (Xianguo Zhou) resolved disagreements. Methodological quality of study was assessed as follows: low quality $=0-3$; moderate quality $=4-7$; high quality $=8-11$.

\section{Data synthesis and statistical analysis}

For the purpose of the current study, STATA 15/SE (Stata Corp LP, College Station, TX, USA) was used for statistical analysis. As it is impossible to assume a true effect size due to the different study populations, regions, and assessment methods across studies, a random-effects model (DerSimonian \& Laird, 1986) ${ }^{19}$ was used to extract the pooled prevalence. Tests of heterogeneity were conducted using $P$ statistics and the Cochran's $Q$ test. Sensitivity analysis was performed by subtracting each study and calculating the pooled prevalence of the remaining studies to identify studies that may severely affect the pooled prevalence ${ }^{20}$. High heterogeneity was defined as $R^{2}>75 \%$ and $P<0.05$ was regarded to be statistically significant.

\section{Results}

\section{Eligible studies and study characteristics}

A PRISMA diagram was used to illustrate the study selection in Fig. 1. After searching electronic databases, 161 relevant studies were found. Among these studies, 70 duplicate studies were removed, and 74 studies were excluded after reviewing their titles and abstracts. 17 studies were identified and searched for full-text screening, of which 8 studies did not meet the inclusion criteria. Among the 8 studies, 1 was not conducted on patients with malignant tumors, and 7 did not assess the prevalence of anxiety and depression. Eventually, 9 studies ${ }^{21-29}$ with 2,335 participants were included in the analysis. All studies were cross-sectional studies and reported the prevalence of anxiety and depression in patients with malignant tumors during the COVID-19 pandemic (Fig. 1).

Table 1 summarizes the characteristics of each study, including the author's name, sample size, country or region, number of males, assessment methods used and their cut-offs, and the percentage of anxiety or depression cases. Of these 9 studies, 7 were conducted in Mainland China, 2 of which were conducted in Wuhan ${ }^{22,23}, 1$ study was conducted in Hong Kong, China ${ }^{21}$, and the other was conducted in New York, $\mathrm{USA}^{24}$. All selected studies were evaluated for methodological quality. One study was of high quality, one study was of low quality, and the other studies were of medium quality (Table 1). 
Table 1

Summary of characteristics of included studies

\begin{tabular}{|c|c|c|c|c|c|c|c|c|}
\hline Author & $\begin{array}{l}\text { sample } \\
\text { size }\end{array}$ & Region & Male & Assessment & $\begin{array}{l}\text { Cut- } \\
\text { off }\end{array}$ & $\begin{array}{l}\text { Anxiety } \\
\mathrm{n}(\%)\end{array}$ & $\begin{array}{l}\text { Depression } \\
\text { n (\%) }\end{array}$ & $\begin{array}{l}\text { Quality } \\
\text { Score }\end{array}$ \\
\hline $\begin{array}{l}\text { Yang } \\
\text { YL.et } \\
\text { al }\end{array}$ & 50 & $\begin{array}{l}\text { Guangzhou, } \\
\text { China }\end{array}$ & 32 & SAS & $\geq$ & $\begin{array}{l}36 \\
(72.00 \%)\end{array}$ & N.A. & 4 \\
\hline $\begin{array}{l}\text { Chen } \\
\text { DM.et } \\
\text { al }\end{array}$ & 625 & China & 0 & HADS & $\geq 8$ & $\begin{array}{l}142 \\
(22.72 \%)\end{array}$ & $\begin{array}{l}126 \\
(20.16 \%)\end{array}$ & 5 \\
\hline $\begin{array}{l}\text { Shi F.et } \\
\text { al }\end{array}$ & 60 & Xian, China & 28 & SAS & $\geq$ & $\begin{array}{l}32 \\
(53.33 \%)\end{array}$ & N.A. & 7 \\
\hline \multirow{2}{*}{$\begin{array}{l}\text { Zhao } \\
\text { MM.et } \\
\text { al }\end{array}$} & \multirow[t]{2}{*}{150} & \multirow{2}{*}{$\begin{array}{l}\text { Changsha, } \\
\text { China }\end{array}$} & \multirow[t]{2}{*}{88} & PHQ-9 & $\geq 6$ & \multirow{2}{*}{$\begin{array}{l}105 \\
(70.00 \%)\end{array}$} & \multirow{2}{*}{$\begin{array}{l}95 \\
(63.33 \%)\end{array}$} & \multirow[t]{2}{*}{7} \\
\hline & & & & GAD-7 & $\geq 6$ & & & \\
\hline \multirow{2}{*}{$\begin{array}{l}\text { Xu } \\
\text { HY.et } \\
\text { al }\end{array}$} & \multirow[t]{2}{*}{368} & \multirow[t]{2}{*}{ China } & \multirow[t]{2}{*}{169} & SAS & $\geq$ & \multirow{2}{*}{$\begin{array}{l}274 \\
(74.46 \%)\end{array}$} & \multirow{2}{*}{$\begin{array}{l}194 \\
(52.72 \%)\end{array}$} & \multirow[t]{2}{*}{5} \\
\hline & & & & SDS & $\geq$ & & & \\
\hline $\begin{array}{l}\mathrm{Ng} \\
\text { DWL.et } \\
\text { al }\end{array}$ & 72 & Hong Kong & 0 & HADS & $\geq 8$ & $\begin{array}{l}9 \\
(12.50 \%)\end{array}$ & $\begin{array}{l}11 \\
(15.28 \%)\end{array}$ & 6 \\
\hline \multirow[t]{2}{*}{$\begin{array}{l}\text { Chen } \\
\text { G.et al }\end{array}$} & \multirow[t]{2}{*}{326} & \multirow[t]{2}{*}{$\begin{array}{l}\text { Wuhan, } \\
\text { China }\end{array}$} & \multirow[t]{2}{*}{174} & SAS & \multirow{2}{*}{$\begin{array}{l}\geq \\
\mathbf{5 0} \\
\geq \\
50\end{array}$} & \multirow{2}{*}{$\begin{array}{l}220 \\
(67.48 \%)\end{array}$} & \multirow{2}{*}{$\begin{array}{l}243 \\
(74.54 \%)\end{array}$} & \multirow[t]{2}{*}{4} \\
\hline & & & & SDS & & & & \\
\hline $\begin{array}{l}\text { Yu Q.et } \\
\text { al }\end{array}$ & 129 & $\begin{array}{l}\text { Wuhan, } \\
\text { China }\end{array}$ & N.A. & HADS & $\geq 8$ & $\begin{array}{l}69 \\
(53.49 \%)\end{array}$ & $\begin{array}{l}65 \\
(50.39 \%)\end{array}$ & 3 \\
\hline $\begin{array}{l}\text { Frey } \\
\text { MK.et } \\
\text { al }\end{array}$ & 555 & $\begin{array}{l}\text { New York, } \\
\text { USA }\end{array}$ & N.A. & HADS & $\geq 8$ & $\begin{array}{l}285 \\
(51.35 \%)\end{array}$ & $\begin{array}{l}147 \\
(26.49 \%)\end{array}$ & 8 \\
\hline $\begin{array}{l}\text { Note: SA } \\
\text { Patient } 1 \\
\text { Rating D }\end{array}$ & $\begin{array}{l}\text { Zung } \\
\text { Ith Que } \\
\text { ession }\end{array}$ & $\begin{array}{l}\text {-Rating Anx } \\
\text { nnnaire-9; G, } \\
\text { ale. }\end{array}$ & Scal & $\begin{array}{l}\text { DS = Hospit } \\
\text { lized Anxiet) }\end{array}$ & Anx & $\begin{array}{l}\text { and Dep } \\
\text { Assessr }\end{array}$ & $\begin{array}{l}\text { ssion Scale; } \\
\text { tt; SDS = Zur }\end{array}$ & $\begin{array}{l}\text { Q-9= } \\
\text { Self- }\end{array}$ \\
\hline
\end{tabular}

\section{Anxiety Prevalence}

The prevalence of anxiety was estimated in 9 studies $^{21-29}$. As shown in Fig. 2, the pooled prevalence was $52.94 \%$ (95\% Cl: $\left.36.98 \%-68.91 \%, I^{2}=98.6 \%\right)$. Regarding assessment methods, 4 studies $22,26,28,29$ used the Zung Self-Rating Anxiety Scale (SAS) with a pooled prevalence of $68.10 \%$ (95\% Cl: $60.86 \%-75.34 \%, P^{2}=$ $74.0 \%$ ), 4 studies ${ }^{21,23-25}$ used the Hospital Anxiety and Depression Scale (HADS) with a pooled prevalence 
of $34.98 \%$ (95\% Cl: $\left.15.94 \%-54.02 \%, P^{2}=98.1 \%\right)$, the remaining 1 study ${ }^{27}$ used the Patient Health Questionnaire-9 (PHQ-9) scale. In the sensitivity analysis, after removing each study in turn, the merger rates of the remaining studies were evenly distributed on both sides of the total merger rate. Therefore, excluding the differences between the studies had little effect on the overall merger rate (Fig. 3).

\section{Depression Prevalence}

As shown in Fig. 4, 7 out of the 9 studies $21-25,27,28$ evaluated depression, with a pooled prevalence of 43.25\% (95\% Cl: $\left.25.85 \%-60.85 \%, P^{2}=98.8 \%\right)$. Two studies ${ }^{22,28}$ used the Zung Self-Rating Depression Scale (SDS) with a pooled prevalence of $63.65 \%\left(95 \% \mathrm{Cl}: 42.27 \%-85.03 \%, \ell^{2}=97.4 \%\right)$. Four studies $21,23-25$ used the HADS score with a pooled prevalence of $27.67 \%(95 \% \mathrm{Cl} ; 17.67 \%-37.66 \%, R=93.7 \%)$. Only one study 27 used the Generalized Anxiety Disorder Assessment (GAD-7) scale. In the sensitivity analysis, after removing each study in turn, the merger rates of the remaining studies were evenly distributed on both sides of the total merger rate. Therefore, excluding the differences between the studies had little effect on the overall merger rate (Fig. 5).

\section{Discussion}

The COVID-19 pandemic has made a profound impact on all aspects of society. For humans, these include not only physical but also psychological effects. Collecting high-quality data to assess the mental health impact of the COVID-19 pandemic on the entire population, especially vulnerable groups (such as cancer patients) is an urgent area for research ${ }^{24}$. This aid understanding of the mental health status of vulnerable groups and can provide a basis for psychological intervention during a pandemic.

This systematic review and meta-analysis of 9 cross-sectional studies with 2,335 participants provided evidence. Our results showed that the prevalence of anxiety and depression in patients with malignant tumors was $53.17 \%$ and $46.08 \%$ respectively. It revealed that factors such as fear, worry, and treatment interruptions during the COVID-19 pandemic resulted in a considerable proportion of patients with malignant tumors experiencing anxiety and depression. This result is not only higher than that during the non-epidemic period ${ }^{10,11}$, but also higher than the prevalence of anxiety and depression in the general population and healthcare workers during the COVID-19 pandemic ${ }^{30-32}$. Studies have shown that anxiety and depression not only reduce the compliance of cancer patients with drug treatment ${ }^{33,34}$, but also affect the body's immune system to recognize and kill tumor cells, leading to immunosuppression and increasing their risk of death ${ }^{35,36}$. In recent years, due to the high prevalence of anxiety in cancer patients, it has been designated as the sixth vital sign of cancer patients 37,38 and many countries have adopted anxiety as a routine screening item for cancer patients ${ }^{39}$ and its reduction as an index of efficacy evaluation ${ }^{40,41}$. Therefore, in response to the rising prevalence of anxiety and depression in cancer patients caused by the sudden international public health emergency, the COVID-19 pandemic, early targeted intervention measures should be considered ${ }^{41}$. 
Early, effective, and timely intervention can not only reduce the incidence of unhealthy emotions and their psychological pressure in cancer patients, but also help patients receive anti-tumor and symptomatic supportive treatment with a better attitude and improve their treatment efficacy and prognosis. In recent years, Mindfulness-based Therapy (MBT) has become an increasingly popular psychological intervention method for cancer patients. The current research results show that the anxiety, depression, and stress of different types of cancer patients were significantly reduced after receiving MBT, with improved quality of life, post-traumatic growth, and mindfulness attitudes ${ }^{42-44}$. In addition, previous studies have also proposed the use of psychological education ${ }^{45}$, group therapy ${ }^{46}$, structured counseling ${ }^{47}$, self-esteem training ${ }^{48}$, and cognitive behavioral therapy ${ }^{49}$ to provide psychological interventions for cancer patients. These measures have a positive effect on alleviating the anxiety and depression of cancer patients. However, there is an urgent need for more rigorous research before recommending specific psychological interventions for cancer patients ${ }^{50}$.

It is worth noting that the results of our study show a high level of heterogeneity, which means that the prevalence of anxiety and depression is quite different in the included studies. Due to limited conditions, we only performed a subgroup analysis of the assessment methods. Although we still observed large heterogeneity, the sensitivity analysis suggests that when a certain study is removed, we can still obtain robust results. Heterogeneity between studies may be due to differences in many factors such as the severity of cancer, cancer treatment status, the prevalence of COVID-19 in different countries or regions, or how cancer patients are treated in different regions.

To our knowledge, the present study is the first systematic review and meta-analysis of the comprehensive prevalence of anxiety and depression in cancer patients during the COVID-19 outbreak. However, our review still has some limitations. Since various studies are cross-sectional, the prevalence of anxiety and depression will also change with the passage of the epidemic. Therefore, the results of anxiety and depression obtained in a certain study may only represent the level during that certain period of the epidemic. Different assessment methods were also used in the studies, and some of them were convenience sampling, snowball sampling, or online survey. It was thus difficult to reflect the diversity of research representatives, and the research results obtained may have bias. In addition, although we conducted extensive searches in different databases, most of the included studies were conducted in Mainland China and Hong Kong, China. Only one study was conducted in New York, USA. The generalization of our research results is also subject to certain restrictions. Given that the COVID-19 epidemic in countries around the world has led to delayed surgeries and treatment interruption for cancer patients ${ }^{51-54}$, it is reasonable to believe that the prevalence of anxiety and depression among cancer patients in other countries or regions also increased significantly, and psychological interventions targeting this group is necessary.

\section{Conclusion}

Our systematic review and meta-analysis combined available evidence in a timely and comprehensive manner to highlight the high prevalence of depression and anxiety in cancer patients during the COVID-19 
pandemic. The results help to quantify the incidence of negative emotions in cancer patients during the COVID-19 epidemic, thus providing information for effective targeted psychological interventions targeting this population.

\section{Declarations}

\section{Ethics approval and consent to participate}

Not applicable.

\section{Consent for publication}

Not applicable.

\section{Availability of data and materials}

Datasets are available through the corresponding author upon reasonable request.

\section{Competing interests}

There are no conflicts of interest.

\section{Funding}

Not applicable.

\section{Authors' contributions}

Hongping Yu, Zewen Zhou and Qiuyan Mo designed the study. Zewen Zhou, Qiuyan Mo, Xianguo Zhou and Yingchun Liu did the literature search. Qiuyan Mo did the systematic review analysis. Qiuyan Mo and Shixiong Feng created the tables. Zewen Zhou and Qiuyan Mo created the draft of the manuscript. Hongping Yu, Xianguo Zhou and Yingchun Liu suggested improvements. Hongping Yu supervised the publication and reviewed the manuscript. All authors have read and approved the content of the manuscript.

\section{Acknowledgements}

Thanks to Chen Huijuan for supporting language editing.

\section{References}

1. Wang C, Horby PW, Hayden FG, et al. A novel coronavirus outbreak of global health concern. Lancet. 2020;395(10223):470-473.

2. Huang C, Wang Y, Li X, et al. Clinical features of patients infected with 2019 novel coronavirus in Wuhan, China. Lancet. 2020;395(10223):497-506. 
3. Hoffman KE. Wait and Hurry Up: Radiation Therapy for Prostate Cancer During the COVID-19 Pandemic. Int J Radiat Oncol Biol Phys. 2020;108(2):340.

4. Verma AM, Nagpal JK. Gastrointestinal cancer pathways may breakdown due to COVID-19. Frontline Gastroenterol. 2020;11(5):413.

5. Siker ML, Deville C, Jr., Suneja G, et al. Lessons From COVID-19: Addressing Health Equity in Cancer Care. Int J Radiat Oncol Biol Phys. 2020;108(2):475-478.

6. Burki TK. Cancer care in the time of COVID-19. Lancet Oncol. 2020;21(5):628.

7. Vanni G, Pellicciaro M, Materazzo M, et al. Lockdown of Breast Cancer Screening for COVID-19: Possible Scenario. In Vivo. 2020;34(5):3047-3053.

8. The Lancet Gastroenterology $\mathrm{H}$. Resuming bowel cancer screening post-COVID-19. Lancet Gastroenterol Hepatol. 2020;5(8):711.

9. Spratt DE. Cancer Treatment Decision-Making During the COVID-19 Pandemic: Data Over Opinion. Int J Radiat Oncol Biol Phys. 2020;108(2):338-339.

10. Linden W, Vodermaier A, Mackenzie R, et al. Anxiety and depression after cancer diagnosis: prevalence rates by cancer type, gender, and age. J Affect Disord. 2012;141(2-3):343-351.

11. Mitchell AJ, Chan M, Bhatti H, et al. Prevalence of depression, anxiety, and adjustment disorder in oncological, haematological, and palliative-care settings: a meta-analysis of 94 interview-based studies. Lancet Oncol. 2011;12(2):160-174.

12. Steel Z, Marnane C, Iranpour C, et al. The global prevalence of common mental disorders: a systematic review and meta-analysis 1980-2013. Int J Epidemiol. 2014;43(2):476-493.

13. Pitman A, Suleman S, Hyde N, et al. Depression and anxiety in patients with cancer. BMJ. 2018;361:k1415.

14. Arrieta O, Angulo LP, Nunez-Valencia C, et al. Association of depression and anxiety on quality of life, treatment adherence, and prognosis in patients with advanced non-small cell lung cancer. Ann Surg Oncol. 2013;20(6):1941-1948.

15. Mystakidou K, Tsilika E, Parpa E, et al. Assessment of anxiety and depression in advanced cancer patients and their relationship with quality of life. Qual Life Res. 2005;14(8):1825-1833.

16. Liberati A, Altman DG, Tetzlaff J, et al. The PRISMA statement for reporting systematic reviews and meta-analyses of studies that evaluate healthcare interventions: explanation and elaboration. BMJ. 2009;339:b2700.

17. Stroup DF, Berlin JA, Morton SC, et al. Meta-analysis of observational studies in epidemiology: a proposal for reporting. Meta-analysis Of Observational Studies in Epidemiology (MOOSE) group. JAMA. 2000;283(15):2008-2012.

18. Rostom A, Dubé C, A. C, et al. Celiac Disease.Rockville (MD) : Rockville (MD): Agency for Healthcare Research and Quality (US); (Evidence Reports/Technology Assessments, No. 104). Appendix D. Quality Assessment Forms. Rockville (MD): Agency for Healthcare Research and Quality (US). https://www.ncbi.nIm.nih.gov/books/NBK35156/. Published 2004 Sep. Accessed.

19. DerSimonian R, Laird N. Meta-analysis in clinical trials. Control Clin Trials. 1986;7(3):177-188. 
20. Fan D, Wu S, Liu L, et al. Prevalence of antepartum hemorrhage in women with placenta previa: a systematic review and meta-analysis. Sci Rep. 2017;7:40320.

21. Ng DWL, Chan FHF, Barry TJ, et al. Psychological distress during the 2019 Coronavirus Disease (COVID-19) pandemic among cancer survivors and healthy controls. Psychooncology. 2020.

22. Chen $\mathrm{G}, \mathrm{Wu} \mathrm{Q}$, Jiang $\mathrm{H}$, et al. Fear of disease progression and psychological stress in cancer patients under the outbreak of COVID-19. Psychooncology. 2020.

23. Qian $\mathrm{Y}, \mathrm{Wu} \mathrm{K}, \mathrm{Xu} \mathrm{H}$, et al. A Survey on Physical and Mental Distress among Cancer Patients during the COVID-19 Epidemic in Wuhan, China. J Palliat Med. 2020;23(7):888-889.

24. Frey MK, Ellis AE, Zeligs K, et al. Impact of the coronavirus disease 2019 pandemic on the quality of life for women with ovarian cancer. Am J Obstet Gynecol. 2020.

25. Chen D, Zhang Y, Lv L, et al. A survey of treatment and psychological status of breast cancer patients during the pandemic of COVID-19. Modern Oncology. 2020;28(12):2179-2182. (in Chinese).

26. Shi F, Liu Z, Zhang Y, et al. Study of the anxiety status and influencing factors of tumor patients during the epidemic of COVID-19. Modern Oncology. 2020;28(09):1608-1610. (in Chinese).

27. Zhao M, Peng D, Liu Q, et al. Investigation on meetal status of patients with hematological malignancies during the COVID-19 outhreak and related influencing factors. Nursing of Integrated Traditional Chinese and Western Medicine. 2020;6(03):38-41. (in Chinese).

28. Xu H, Yang K, Yang G, et al. Explore the Optimal Resolvent of Medical Needs and Mental Health for Patients with Lung Cancer during Epidemic Novel Coronavirus Pneumonia. Chin J Lung Cancer. 2020;23(04):247-254. (in Chinese).

29. Yang Y, Zhong L, Peng L. Investigation and analysis of the psychological status of cancer patients during the novel coronavirus pneumonia epidemic. Chinese General Practice Nursing. 2020;18(06):691-693. (in Chinese).

30. Salari N, Hosseinian-Far A, Jalali R, et al. Prevalence of stress, anxiety, depression among the general population during the COVID-19 pandemic: a systematic review and meta-analysis. Global Health. 2020;16(1):57.

31. Pappa S, Ntella V, Giannakas T, et al. Prevalence of depression, anxiety, and insomnia among healthcare workers during the COVID-19 pandemic: A systematic review and meta-analysis. Brain Behav Immun. 2020;88:901-907.

32. Gao J, Zheng P, Jia Y, et al. Mental health problems and social media exposure during COVID-19 outbreak. PLoS One. 2020;15(4):e0231924.

33. DiMatteo MR, Lepper HS, Croghan TW. Depression is a risk factor for noncompliance with medical treatment: meta-analysis of the effects of anxiety and depression on patient adherence. Arch Intern Med. 2000;160(14):2101-2107.

34. Greer JA, Pirl WF, Park ER, et al. Behavioral and psychological predictors of chemotherapy adherence in patients with advanced non-small cell lung cancer. J Psychosom Res. 2008;65(6):549-552.

35. Pinquart M, Duberstein PR. Depression and cancer mortality: a meta-analysis. Psychol Med. 2010;40(11):1797-1810. 
36. Satin JR, Linden W, Phillips MJ. Depression as a predictor of disease progression and mortality in cancer patients: a meta-analysis. Cancer. 2009;115(22):5349-5361.

37. Bultz BD, Carlson LE. Emotional distress: the sixth vital sign in cancer care. J Clin Oncol. 2005;23(26):6440-6441.

38. Holland JC, Bultz BD, National comprehensive Cancer N. The NCCN guideline for distress management: a case for making distress the sixth vital sign. J Natl Compr Canc Netw. 2007;5(1):3-7.

39. Bultz BD. Patient Care and Outcomes: Why Cancer Care Should Screen for Distress, the 6(th) Vital Sign. Asia Pac J Oncol Nurs. 2016;3(1):21-24.

40. Bultz BD, Carlson LE. Emotional distress: the sixth vital sign-future directions in cancer care. Psychooncology. 2006;15(2):93-95.

41. Howell D, Olsen K. Distress-the 6th vital sign. Curr Oncol. 2011;18(5):208-210.

42. Zhang MF, Wen YS, Liu WY, et al. Effectiveness of Mindfulness-based Therapy for Reducing Anxiety and Depression in Patients With Cancer: A Meta-analysis. Medicine (Baltimore). 2015;94(45):e08970890.

43. Zhang J, Xu R, Wang B, et al. Effects of mindfulness-based therapy for patients with breast cancer: A systematic review and meta-analysis. Complement Ther Med. 2016;26:1-10.

44. Hofmann SG, Sawyer AT, Witt AA, et al. The effect of mindfulness-based therapy on anxiety and depression: A meta-analytic review. J Consult Clin Psychol. 2010;78(2):169-183.

45. Faller $\mathrm{H}$, Schuler $\mathrm{M}$, Richard $\mathrm{M}$, et al. Effects of psycho-oncologic interventions on emotional distress and quality of life in adult patients with cancer: systematic review and meta-analysis. $J$ Clin Oncol. 2013;31(6):782-793.

46. Bellver-Perez A, Peris-Juan C, Santaballa-Beltran A. Effectiveness of therapy group in women with localized breast cancer. Int J Clin Health Psychol. 2019;19(2):107-114.

47. Trijsburg RW, van Knippenberg FC, Rijpma SE. Effects of psychological treatment on cancer patients: a critical review. Psychosom Med. 1992;54(4):489-517.

48. Vidthya $S$, Sherina MS, Rampal L, et al. Self-esteem among cancer patients receiving chemotherapy in selected. Med J Malaysia. 2019;74(5):405-412.

49. Carbajal-Lopez EB, Juarez-Garcia DM, Espinoza-Velazco A, et al. Internet-Delivered Cognitive Behavioral Therapy and Psychoeducation Program for Patients with Gastrointestinal Stromal Tumors. J Cancer Educ. 2020.

50. Piet J, Wurtzen $\mathrm{H}$, Zachariae R. The effect of mindfulness-based therapy on symptoms of anxiety and depression in adult cancer patients and survivors: a systematic review and meta-analysis. $J$ Consult Clin Psychol. 2012;80(6):1007-1020.

51. Kutikov A, Weinberg DS, Edelman MJ, et al. A War on Two Fronts: Cancer Care in the Time of COVID19. Ann Intern Med. 2020;172(11):756-758.

52. van de Haar J, Hoes LR, Coles CE, et al. Caring for patients with cancer in the COVID-19 era. Nat Med. 2020;26(5):665-671. 
53. Zhao W, Qiu H, Gong Y, et al. Clinical considerations for the management of cancer patients in the mitigation stage of the COVID-19 pandemic. Am J Cancer Res. 2020;10(8):2282-2292.

54. Tzeng CD, Tran Cao HS, Roland CL, et al. Surgical decision-making and prioritization for cancer patients at the onset of the COVID-19 pandemic: A multidisciplinary approach. Surg Oncol. 2020;34:182-185.

\section{Figures}

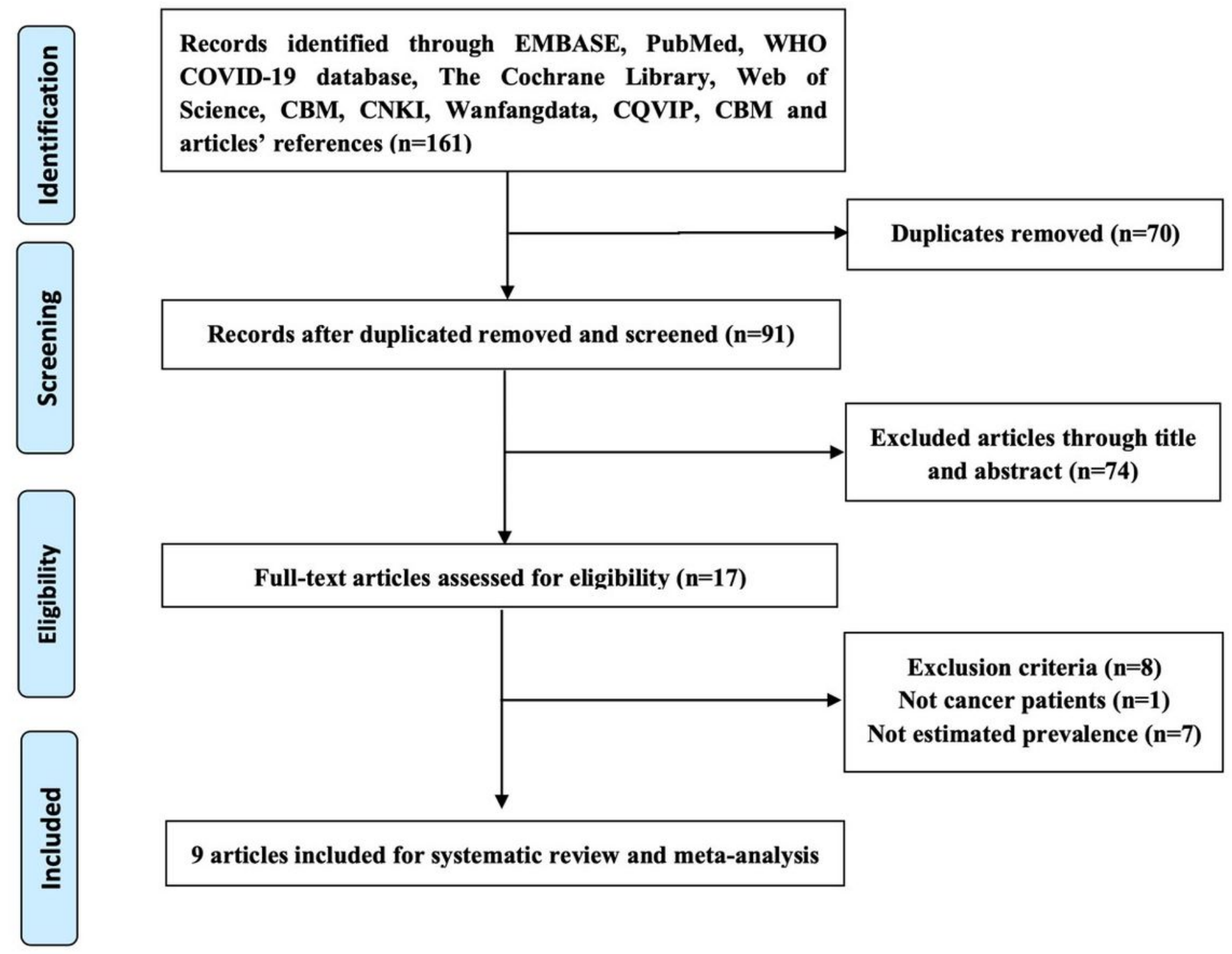

Figure 1

Flow chart of study selection process 


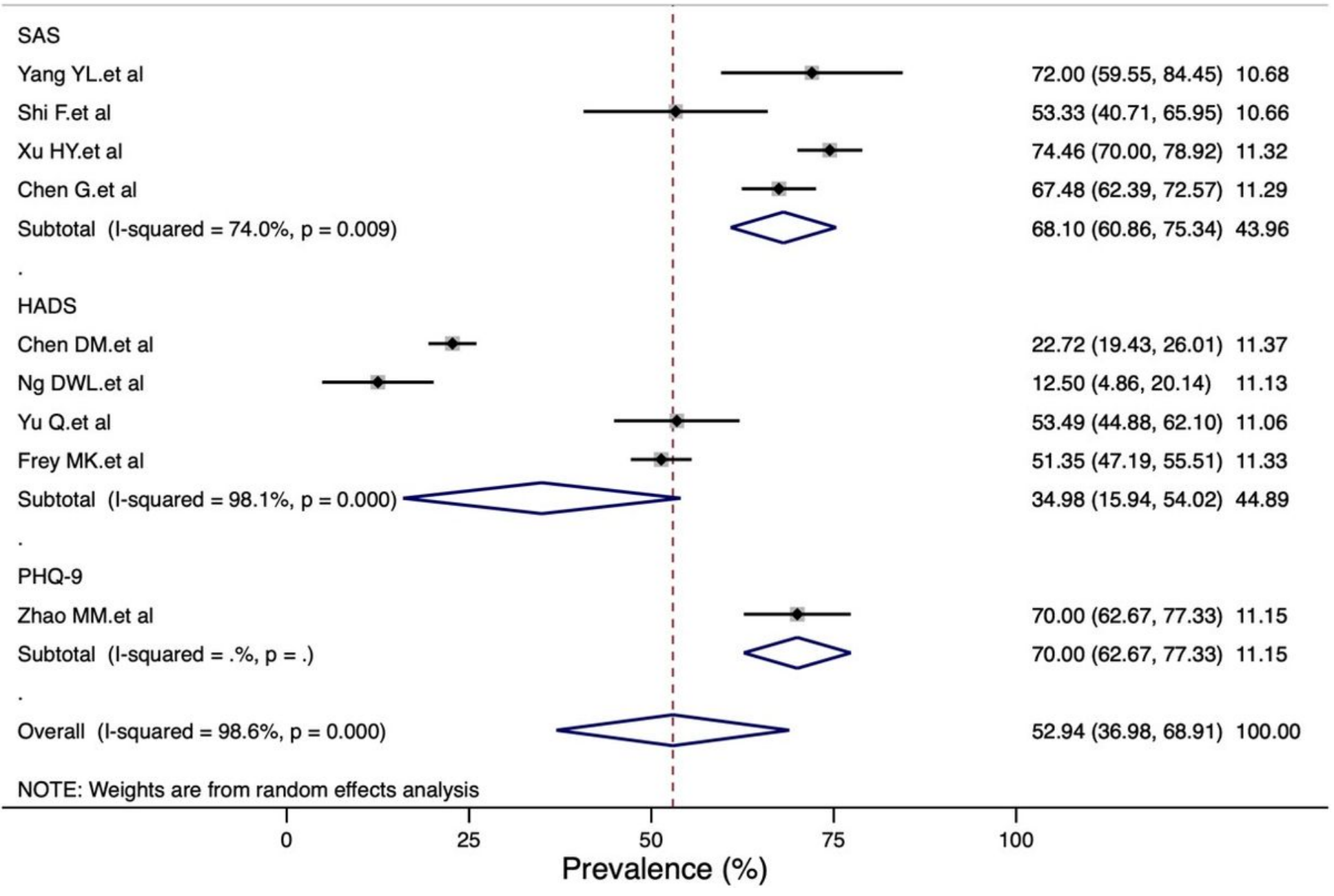

Figure 2

Total pooled anxiety prevalence by assessment method 


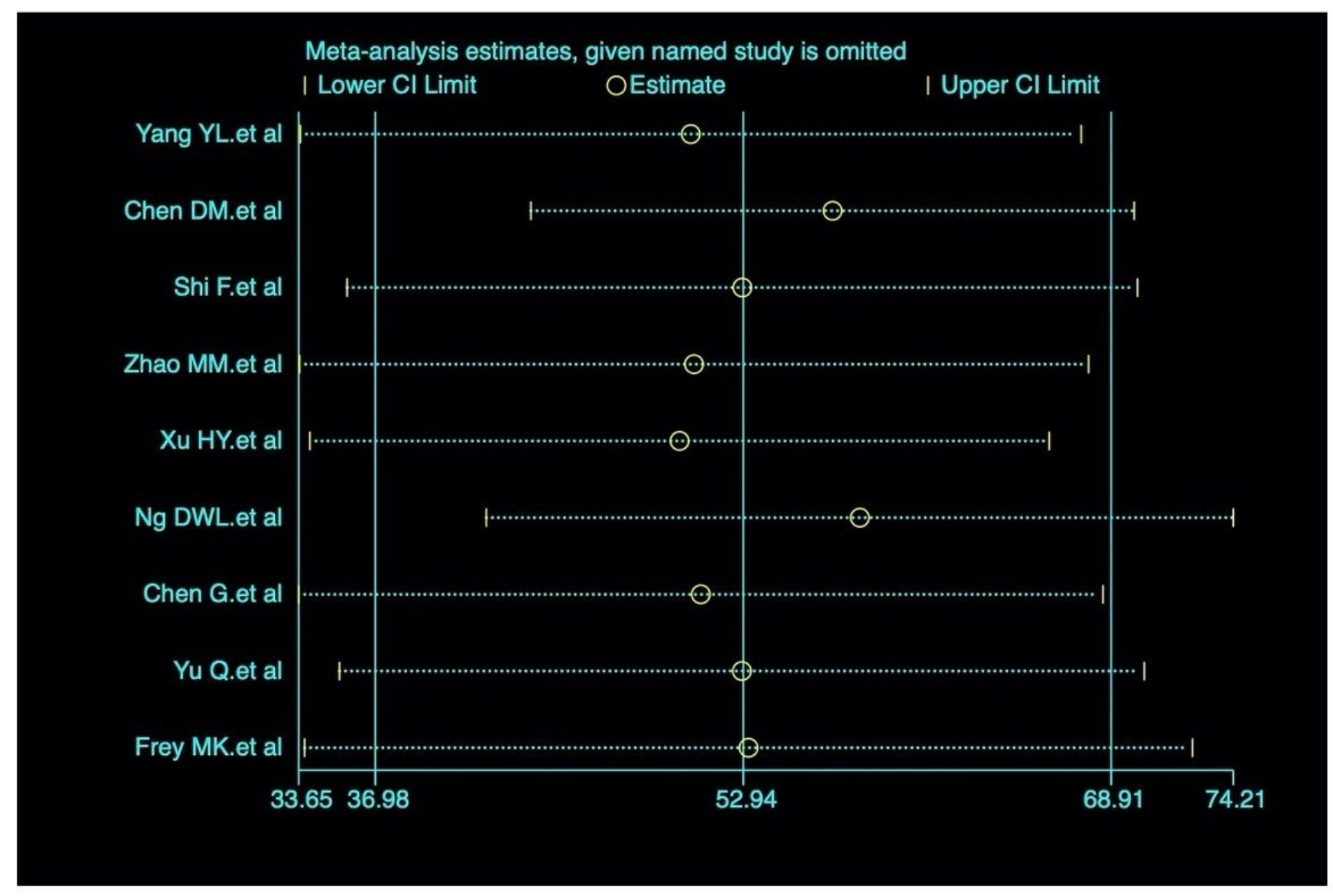

\section{Figure 3}

Sensitivity analysis of pooled anxiety prevalence 
HADS

Chen DM.et al

$\mathrm{Ng}$ DWL.et al

$20.16(17.01,23.31) 14.48$

Yu Q.et al

Frey MK.et al

Subtotal (I-squared $=93.7 \%, p=0.000$ )

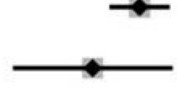

$15.28(6.97,23.59) \quad 14.09$

$50.39(41.76,59.02) \quad 14.05$

26.49 (22.82, 30.16) 14.46

$27.67(17.67,37.66) 57.08$

$63.33(55.62,71.04) \quad 14.15$

$63.33(55.62,71.04) \quad 14.15$

Subtotal (I-squared $=. \%, p=$.)

SDS

Xu HY.et al

Chen G.et al

Subtotal (I-squared $=97.4 \%, p=0.000$ )

Overall (I-squared $=98.8 \%, p=0.000$ )

NOTE: Weights are from random effects analysis

$\begin{array}{ccccc}1 & 1 & 1 & 1 \\ 0 & 25 & 50 & 75 & 100\end{array}$

$52.72(47.62,57.82) \quad 14.37$

74.54 (69.81, 79.27) 14.40

$63.65(42.27,85.03) 28.77$

$43.25(25.85,60.65) \quad 100.00$

\section{Figure 4}

Total pooled depression prevalence by assessment method 


\section{Meta-analysis estimates, given named study is omitted}

I Lower CI Limit

Yang YL.et al
Chen DM.et al

Shi F.et al

Zhao MM.et al

Xu HY.et al

$\mathrm{Ng}$ DWL.et al

Chen G.et al

Yu Q.et al

Frey MK.et al
OEstimate

I Upper CI Limit

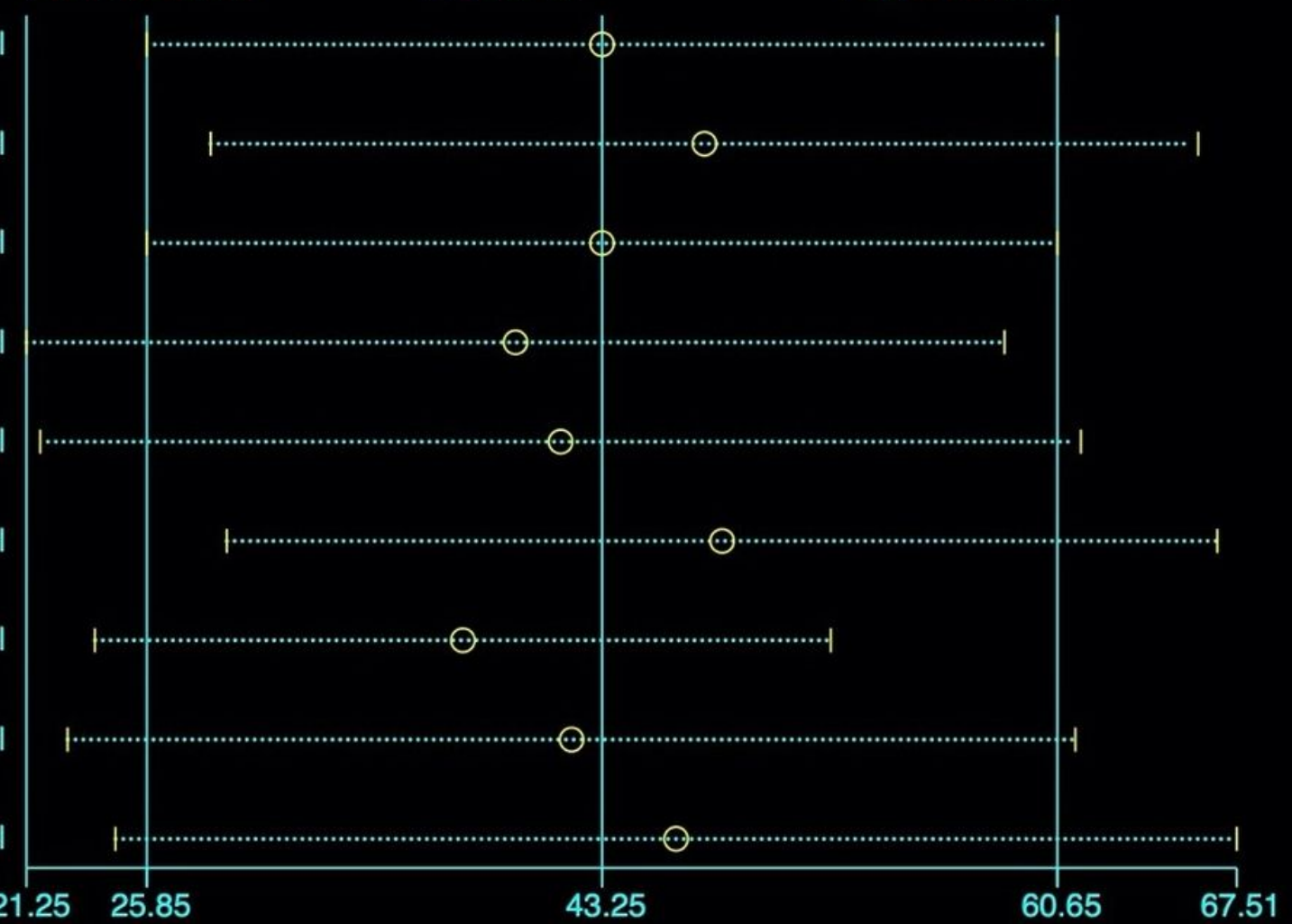

\section{Figure 5}

Sensitivity analysis of pooled depression prevalence 